\title{
Use of Isoprenaline as an Antiarrhythmic Agent After Valve Replacement Surgery
}

\author{
JOHN F. GUNNING ${ }^{\star}$ MARK X. SHANAHAN, AND HARRY M. WINDSOR \\ From St. Vincents Hospital, Sydney, N.S.W., Australia
}

The sympathomimetic drugs are generally considered to increase cardiac automaticity, thus predisposing to ventricular ectopic beats, ventricular tachycardia, and ventricular fibrillation (Foster, 1966; Hellerstein, Brofman, and Caskey, 1952). This paper describes the use of isoprenaline, a sympathomimetic drug, as an antiarrhythmic agent in three patients. These patients were having recurrent ventricular tachycardia and ventricular fibrillation in the early post-operative period after cardiac valve replacement.

\section{CASE RePorts}

Case 1. A married woman, aged 53 years, had become increasingly breathless over 10 years. This was accompanied by lethargy and recurrent bronchitis and orthopnoea. The clinical signs of mitral stenosis, aortic stenosis and incompetence, and tricuspid incompetence were present. Chest $x$-ray showed biventricular and left atrial enlargement, increased pulmonary vascular markings, and septal lymphatic lines. Electrocardiogram showed atrial fibrillation and left ventricular hypertrophy. Cardiac catheterization and cine-angiography confirmed the clinical diagnosis. Both the mitral and aortic valves were calcified.

Aortic replacement with a No. 8 Starr-Edwards prosthesis, mitral commissurotomy, and tricuspid valve annuloplasty were performed. Two hours after operation carried out on January 26, 1967, the electrocardiogram showed atrial fibrillation with ventricular bigeminy (Fig. A). Serum potassium was $2.0 \mathrm{mEq} / \mathrm{litre}$, and 50 $\mathrm{mEq}$ potassium were given by infusion in the following 3 hours. After this ventricular bigeminy ceased. Serum potassium 5 hours after operation was $3.3 \mathrm{mEq} /$ litre. Four hours later ventricular bigeminy again developed and was followed by short episodes of ventricular tachycardia and fibrillation which reverted spontaneously (Fig. B). Procainamide $500 \mathrm{mg}$. intravenously, and $40 \mathrm{mEq} /$ litre potassium by intravenous infusion were given. An hour later ventricular fibrilla-

Received May 16, 1968.

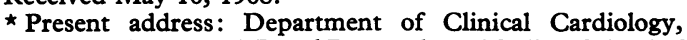
Hammersmith Hospital, Royal Postgraduate Medical School of London, DuCane Road, London W.12. tion occurred and in the subsequent 90 minutes, 50 defibrillations were performed. Procainamide 500 mg. was repeated and lignocaine $40 \mathrm{mg}$. was given at 10-minute intervals for 5 doses without effect. Between episodes of ventricular fibrillation, the cerebral state was lucid and the systemic blood pressure was 115/70 $\mathrm{mm}$. Hg. An hour later an isoprenaline infusion, $1 \mathrm{mg}$. in $500 \mathrm{ml} .5 \%$ dextrose in water, was begun. Almost immediately the episodes of ventricular arrhythmia ceased. Blood pressure remained at $120 / 80 \mathrm{~mm}$. $\mathrm{Hg}$. Two hours later episodes of ventricular tachycardia recurred followed by ventricular fibrillation requiring electric countershock When the rate of the isoprenaline infusion was increased, the arrhythmias ceased (Fig. C). Between 17 hours and 21 hours after the operation 100 defibrillations were necessary. During this period, isoprenaline infusion, $2 \mathrm{mg}$. in $500 \mathrm{ml}$., was continued. Other treatment included an infusion of lignocaine $300 \mathrm{mg}$., digoxin $0.5 \mathrm{mg}$. intravenously, procainamide $500 \mathrm{mg}$. intramuscularly six-hourly, and potassium $10 \mathrm{mEq} /$ litre/hour intravenously. Subsequent serum potassium estimations were $4.0 \mathrm{mEq} /$ litre or greater. During this period the electrocardiogram monitor revealed that as the rate of the isoprenaline infusion was increased the ventricular rate also increased and the episodes of ventricular arrhythmia became less frequent. When this was observed, higher concentrations of isoprenaline were used.

Twenty-three hours after the operation $11 \mathrm{mg}$. isoprenaline had been given. No further defibrillations were necessary on that day, but the cardiac rhythm remained unstable. If the rate of the infusion was slowed, episodes of ventricular tachycardia occurred but were immediately suppressed if the rate was increased. During the next few days, increasing concentrations of isoprenaline were required to prevent ventricular fibrillation. During one two-hour period $20 \mathrm{mg}$. isoprenaline were required. During the 10 days after operation a total of $124 \mathrm{mg}$. isoprenaline was given and 10 further defibrillations were required. Some agitation and disorientation were noted on one day, but these responded, over 24 hours, to chlorpromazine.

On February 6, isoprenaline was suspended but procainamide $500 \mathrm{mg}$. six-hourly was continued. Convalescence was thereafter uneventful. The patient was discharged on February 14, at which time she was bright and alert mentally, and appeared to have suffered no ill 


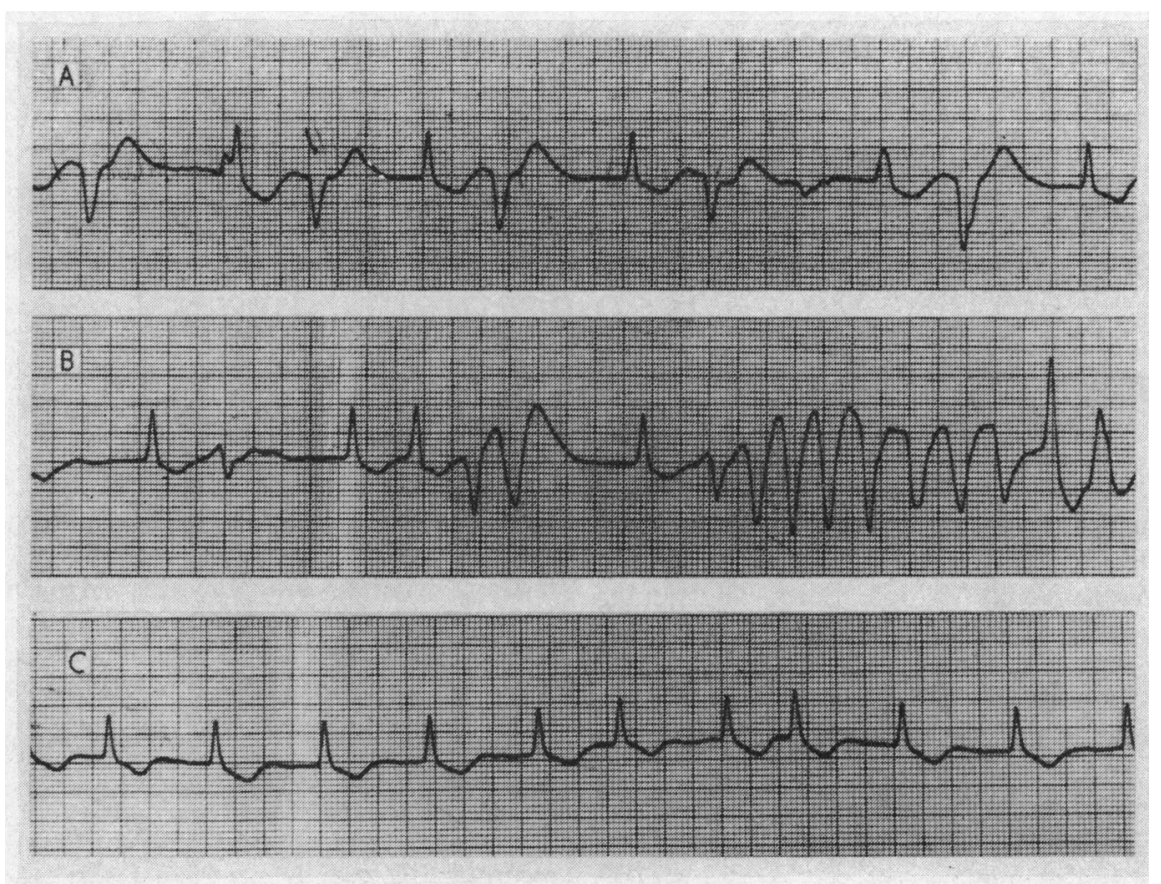

FIG.-Examples of the electrocardiogram in Case 1. (A) 2 hours after operation, atrial fibrillation with ventricular bigeminy. (B) Seven hours later, short episodes of spontaneously reverting ventricular tachycardia and fibrillation. (C) Fourteen hours after operation, atrial fibrillation with a ventricular rate of approximately 92 a minute during rapid infusion of isoprenaline.

effects from her 160 defibrillations. At the present time she is well and fully active.

Case 2. A 49-year-old man had a mitral valvotomy in 1955. From 1961 he had experienced increasing dyspnoea, orthopnoea, paroxysmal nocturnal dyspnoea, recurrent respiratory infections, and recurrent ankle swelling. When admitted in March 1967, he had the signs of mitral stenosis and incompetence and tricuspid incompetence. The electrocardiogram showed atrial fibrillation with right bundle-branch block. The chest $x$-ray showed left ventricular and left atrial enlargement. Cardiac catheterization and cine-angiography confirmed the clinical diagnosis.

At operation on March 30, using a transseptal approach, mitral valve replacement with a No. 4 StarrEdwards prosthesis and tricuspid annuloplasty were performed. Ventricular fibrillation occurred early the next morning, 14 hours after operation. This was immediately converted to sinus rhythm by electric countershock. Procainamide $1.0 \mathrm{~g}$. intramuscularly was given, followed by $500 \mathrm{mg}$. every 6 hours. The serum potassium was $3 \mathrm{mEq} /$ litre, and $70 \mathrm{mEq} /$ litre potassium were given by infusion over the next 6 hours. Subsequent serum potassium estimations were 4.3 $\mathrm{mEq} /$ litre or higher.

During the next 2 hours, 8 episodes of ventricular fibrillation requiring electric countershock occurred as well as numerous short episodes of self-limiting ventricular tachycardia. An isoprenaline infusion was started.
As the rate of the infusion was increased, the ventricular rate increased and the short episodes of ventricular arrhythmia ceased. The systemic blood pressure was $120 / 90 \mathrm{~mm}$. Hg. Six further episodes of ventricular fibrillation requiring electric countershock occurred during the next 24 hours, but increasing the rate of the isoprenaline infusion immediately reduced the ventricular irritability. A total of $43 \mathrm{mg}$. isoprenaline was infused during the next 4 days. Throughout this period it was noted that whenever the rate of infusion was reduced the ventricular rate slowed and short episodes of ventricular arrhythmia occurred.

On April 3 some agitation and delirium occurred. This responded to large doses of chlorpromazine over 36 hours. By April 5 the cardiac rhythm had become stable and no further isoprenaline was required. Procainamide $500 \mathrm{mg}$. six-hourly was continued for a further 5 days and then discontinued. No further ventricular arrhythmias occurred. He was discharged on May 22, and remains well.

Case 3. A 52-year-old man had a mitral valvotomy in 1953. Symptoms of increasing dyspnoea, orthopnoea, and frequent bronchitis were present in recent years. He suffered a myocardial infarction in 1964.

The signs were those of mitral stenosis and incompetence and aortic stenosis and incompetence. The chest $x$-ray showed gross cardiomegaly with left ventricular and left atrial enlargement. There was pulmonary venous congestion and septal lymphatic lines. 
The electrocardiogram showed atrial fibrillation, ventricular premature contractions, and left ventricular hypertrophy. Cardiac catheterization and cine-angiography confirmed the clinical diagnosis.

At operation on August 3, 1967, the aortic and mitral valves were replaced with Starr-Edwards prostheses.

Two hours after operation, multiple ventricular ectopic beats developed. The systemic blood pressure was $140 / 80 \mathrm{~mm}$. Hg. Procainamide $500 \mathrm{mg}$. intravenously was given with some improvement, and was repeated at four-hourly intervals by intramuscular injection. Serum potassium was $3.5 \mathrm{mEq} / \mathrm{litre}$, and 40 $\mathrm{mEq} /$ litre potassium was given over the next 3 hours. The electrocardiogram showed inferior myocardial infarct pattern, with $Q$ waves, raised $S-T$ segments and inverted $T$ waves in standard leads II and III and in lead aVF. Frequent ventricular ectopic beats recurred with short episodes of ventricular tachycardia. Isoprenaline infusion, $1 \mathrm{mg}$. in $500 \mathrm{ml}$., was started and continued over 5 hours, with some improvement in the rhythm. The concentration was then increased to $3 \mathrm{mg}$. in $500 \mathrm{ml}$. This was infused over 5 hours and resulted in cessation of the ventricular ectopic beats.

At 11.00 a.m. the day after operation, ventricular fibrillation occurred and 8 defibrillations were necessary over a short period. Lignocaine $50 \mathrm{mg}$. intravenously at five-minute intervals for 6 doses was given. Over the subsequent 5 days ventricular arrhythmias occurred frequently, with 70 episodes of ventricular fibrillation necessitating electric countershock. During this period it was evident that an increase in the rate of the isoprenaline infusion depressed ventricular ectopic activity after first increasing the ventricular rate. A total of $350 \mathrm{mg}$. isoprenaline was given. On the sixth day after operation a slow idioventricular rhythm occurred which did not respond to increased infusion, and death occurred in asystole. Necropsy revealed old anterior and posterior myocardial infarction. There was no evident occlusion of the major coronary arteries. There was marked contusion and haematoma formation in the interatrial septum presumably due to retraction during operation. Both prosthetic valves appeared normal and free of thrombus.

\section{Discussion}

Isoprenaline, a derivative of adrenaline in which the methyl group is replaced by an isopropyl group, is a beta-adrenergic agonist. It causes dilatation of voluntary muscle arterioles and probably coronary arterioles as well. It also causes venous constriction (Shepherd, 1966), thereby reducing the capacity of the venous bed. It increases sinus rate, facilitates the passage of impulses across the atrioventricular node, and increases both myocardial contractility and myocardial oxygen consumption.

The use of isoprenaline to increase cardiac rate in complete heart block is well established. Linenthal and Zoll (1963) described its use in conventional dosage to prevent ventricular tachycardia and fibrillation in such patients. They explained that iso- prenaline seemed to increase the idioventricular rate to a certain critical level at which there was less time for ectopic activity to interrupt the basic ventricular rhythm. They pointed out, however, that myocardial irritability could be further aggravated before the cardiac acceleration was adequate to suppress ectopic activity.

It has been accepted that the sympathomimetic amines in sufficiently large dosage will produce ectopic ventricular rhythms (Foster, 1966; Hellerstein et al., 1952). The use of sympathomimetic drugs in suppressing ectopic ventricular rhythms in the absence of complete heart block has also been reported (Gold and Corday, 1959). It was considered that they achieved this by restoring a reduced systemic blood pressure to normal levels. Isoprenaline infused at the rate of $5 \mu \mathrm{g}$. $/ \mathrm{min}$. has been shown to increase heart rate, stroke volume, cardiac output, and systemic blood pressure in patients with shock due to bacterial infections or fluid loss (Bradley and Weil, 1965). None of the patients we have described were hypotensive nor was there evidence of reduced cardiac output between the episodes of ventricular arrhythmia.

Brill, Krueger, and McCawley (1959) noted that methoxamine, whose action is mediated via alpha receptors, would suppress ventricular ectopics in normotensive patients by raising their systemic blood pressure to hypertensive levels. Similarly, Kravetz, Kagan, and Frement (1962) described the use of metaraminol to terminate ventricular tachycardia in a normotensive patient whose pressure rose to $194 / 120 \mathrm{~mm}$. $\mathrm{Hg}$ before reversion occurred. They believed that this increase in blood pressure terminated the paroxysmal tachycardia by increasing a relatively diminished coronary blood flow. The use of isoprenaline in our patients did not produce significant increases of blood pressure.

We have only found documented evidence of the antiarrhythmic effect of isoprenaline in the absence of complete heart block, in two case reports. Underhill and Tredway (1964) described a patient with recurrent ventricular tachycardia which was controlled for 2 weeks with an infusion of isoprenaline; the dosage used was of the order of $0.4 \mathrm{mg}$. every 12 hours, but their patient died after 2 weeks. Nickel and Thibaudeau (1961) reported the use of isoprenaline in the treatment of ventricular flutterfibrillation due to quinidine intoxication; their experience was similar to ours in that slowing the rate of the infusion resulted in various ventricular arrhythmias occurring and increasing the rate resulted in return of supraventricular rhythm. They concluded that isoprenaline stimulated the higher pacemakers that had been depressed by quinidine, thus tending to re-establish the normal inhibition of 
the idioventricular pacemakers by the sino-atrial node. In our cases the antiarrhythmic action of isoprenaline seemed to be related to its chronotropic action. The critical rate above which ventricular arrhythmia did not occur varied, but was usually between 80 and 100 a minute. The dose of isoprenaline required to produce this rate in Case 1 varied greatly from $1 \mathrm{mg}$. over 12 hours to $30 \mathrm{mg}$. over 2 hours during the treatment period. Though the action of isoprenaline in increasing cardiac output and coronary blood flow may also play a part, we believe that it is the increase in heart rate that is most important in suppressing the abnormal ventricular activity. Analogous to this is the use of artificial cardiac pacing at rapid ventricular rates to suppress persistent ventricular arrhythmias, as described by Sowton, Leatham, and Carson (1964), Heiman and Helwig (1966), and Lew and March (1967). The effectiveness of the beta-adrenergic blocking agent propranolol in terminating ventricular arrhythmias has been reported (Sloman, Robinson, and McLean, 1965). One of the other adrenergic drugs, methoxamine, has been demonstrated to have beta-receptor blocking action (Karim, 1965). Isoprenaline, in the massive dosages used in our patients, may have some beta-adrenergic blocking action which contributes to its antiarrhythmic action, tachyphylaxis having developed to its other actions. However, in the early stages of treatment the dosage used was conventional and it was then an effective antiarrhythmic agent before tachyphylaxis could have developed.

The frequency of low serum potassium levels after bypass surgery and their association with ventricular arrhythmias has recently been stressed by Obel, Marchand, and Du Plessis (1966). The low serum potassium levels in our patients immediately after operation may have contributed to the ventricular irritability, but these low levels were rapidly corrected by the intravenous infusion of potassium chloride, and it seems unlikely that hypokalaemia was contributing to the arrhythmias after the first few hours of ventricular irritability.

Though the occurrence of an acute delirium in two of our patients during the administration of these large doses of isoprenaline may have been a side-effect of this drug, it is more likely the delirium was a post-operative psychotic reaction related to multiple episodes of ventricular arrhythmia. In each case it was readily controlled with chlorpromazine.

It is the purpose of this report to draw attention to an antiarrhythmic action of isoprenaline when used in the treatment of recurrent ventricular arrhythmias after heart operations. Our experience with three patients leads us to suggest that it is worth a further trial in the management of this difficult problem. The dosage of isoprenaline which we have found necessary in these three patients is greatly in excess of previously accepted levels, but produced no apparent serious side-effects.

\section{SUMMARY}

The use of an isoprenaline infusion in the management of recurrent ventricular arrhythmias after valve replacement is described in three patients. The dosages of isoprenaline used were large, being $125 \mathrm{mg}$. in 9 days, $43 \mathrm{mg}$. in 4 days, and $350 \mathrm{mg}$. in 6 days, respectively. None of the patients had complete heart block or hypotension and the antiarrhythmic effect was not accompanied by an increase in systemic blood pressure. No serious side-effects were found with these large doses.

\section{REFERENCES}

Bradley, E. C., and Weil, M. H. (1965). Treatment of circulatory shock with a betamimetic agent. Circulation, 32, Suppl. 2, p. 57.

Brill, I. C., Krueger, J. D., and McCawley, E. L. (1959). Restoration of sinus rhythm in experimental and clinical ventricular arrhythmias by methoxamine hydrochloride. Amer. F. Cardiol., 3, 307.

Foster, R. W. (1966). The pharmacology of pressor drugs. Brit. F. Anaesth., 38, 690.

Gold, H., and Corday, E. (1959). Vasopressor therapy in the cardiac arrhythmias. New Engl. f. Med., 260, 1151.

Heiman, D. F., and Helwig, J., Jr. (1966). Suppression of ventricular arrhythmias by transvenous intracardiac pacing. F. Amer. med. Ass., 195, 1150.

Hellerstein, H. K., Brofman, B. L., and Caskey, W. H. (1952). Shock accompanying myocardial infarction: Treatment with pressor amines. Amer. Heart f., 44, 407.

Karim, S. M. M. (1965). Sympathetic $\beta$-receptor blocking action of methoxamine. Brit. F. Pharmacol., 24, 365.

Kravetz, R. E., Kagan, A., and Fremont, R. E. (1962). Termination of rapid ventricular tachycardia with metaraminal (Aramine). Amer. F. Cardiol., 10, 579.

Lew, H. T., and March, H. W. (1967). Control of recurrent ventricular fibrillation by transvenous pacing in the absence of heart block. Amer. Heart F., 73, 794.

Linenthal, A. J., and Zoll, P. M. (1963). Prevention of ventricular tachycardia and fibrillation by intravenous isoproterenol and epinephrine. Circulation, 27, 5.

Nickel, S. N., and Thibaudeau, Y. (1961). Quinidine intoxication treated by isoprenaline (Isuprel). Canad. med. Ass. F., 85, 81.

Obel, I. W. P., Marchand, P., and Du Plessis, L. (1966). Biochemical changes associated with the use of haemodilution with $5 \%$ dextrose in water and mannitol for open-heart surgery. Thorax, 22, 180.

Shepherd, J. P. (1966). Role of the veins in the circulation. Circulation, 33, 484.

Sloman, G., Robinson, J. S., and McLean, K. (1965). Propranolol (Inderal) in persistent ventricular fibrillation. Brit. med. F., 1, 895.

Sowton, E., Leatham, A., and Carson, P. (1964). The suppression of arrhythmias by artificial pacing. Lancet, 2, 1098.

Underhill, W. L., and Tredway, J. B. (1964). The treatment of paroxysmal ventricular tachycardia with isoproterenol Ann. intern. Med., 60, 680. 